\title{
On the Concept of Time in everyday Life and between Physics and Mathematics
}

\author{
Paolo Di Sia ${ }^{1-4}$ \\ ${ }^{1}$ University of Padova, School of Science \& Department of Neuroscience, Via Giustiniani 2, \\ I-35128 Padova (Italy) \\ ${ }^{2}$ Free University of Bozen-Bolzano, Faculty of Science and Technology, Piazza Università 5, \\ I-39100 Bolzano (Italy) \\ ${ }^{3}$ E-mail address: paolo.disia@gmail.com \\ ${ }^{4}$ Web-page: https://www.paolodisia.com
}

In this paper I consider the concept of time in a general way as daily human time and then within physics with relation to mathematics. I focus the attention on quantum mechanics, with its particular peculiarities, examining peculiar important questions like the temporal asymmetry, the Prigogine's position and the time-reversal operator of Wigner. I conclude considering the theme of the temporal asymmetry in relation to decoherence and irreversibility. Interesting imputs related to education science will be done.

Keywords: Time, Quantum Mechanics, Irreversibility, Decoherence, Physics, Mathematics, Symmetry/Asymmetry, Education, Science, Technology. 


\section{References (in progress)}

1. P. Di Sia, On philosophy of mind, quantum physics and metaphysics of the unimultiverse, Preprint DOI: 10.31219/osf.io/7szn5 (2019).

2. P. Di Sia, N. K. Bhadra, Origin of living matter by a new model of consciousness, Preprint DOI: 10.31219/osf.io/h7tud (2019).

3. P. Di Sia, N. K. Bhadra, Origin of consciousness and contemporary physics, World Scientific News, 140, 127-138 (2020).

4. P. Di Sia, A CULTURAL OVERVIEW ON THE CONCEPT OF INFINITY, Journal of Education, Culture and Society, 1(1), 17-38 (2019), doi: 10.15503/jecs20141-9-19.

5. N. K. Bhadra, P. Di Sia, MIND AND CONSCIOUSNESS AS CREATED BY ELECTROMAGNETIC FORCE, International Journal of Applied and Advanced Scientific Research (IJAASR), 4(1), pp. 1-6 (2019), doi: http://doi.org/10.5281/zenodo.2573101.

6. P. Di Sia, Mindfulness, Consciousness and Quantum Physics, World Scientific News, 96, 25-34 (2018).

7. P. Di Sia, Quantum Physics, Metaphysics, Theism: Interpretations, Ontologies, Theological Remarks, World Scientific News, 74, 106-120 (2017).

8. P. Di Sia, About the existence of the universe among speculative physics, metaphysics and theism: an interesting overview, International Letters of Social and Humanistic Sciences (ILSHS), 9(1), 36-43 (2015).

9. P. Di Sia, Approaching youngs to unified theories: the charm of string theories, Procedia - Social and Behavioral Sciences Journal, 174C, 10-16 (2015).

10. P. Di Sia, Looking at the Dimension of Time among Science, Psychology and Everyday Reality, International Letters of Social and Humanistic Sciences (ILSHS), 1(2), 146-153 (2015).

11. P. Di Sia, Exciting Peculiarities of the Extreme Physics, Journal of Physics: Conference Series, 442(1), 012068 (2013).

12. P. Di Sia, Extreme Physics and Informational/Computational Limits, Journal of 
Physics: Conference Series, 306, 012067 (2011).

13. P. Di Sia, Fine-Tuning, Universo, Multiverso - tra Scienza, Filosofia e Teismo, Roma: Aracne Editrice (2019), ISBN 978-88-255-2943-2.

14. P. Di Sia, FISICA MODERNA, COSCIENZA, MULTIVERSO, AZIONE DIVINA - Problemi, dubbi, convergenze, Roma: Stamen (Series: The Human and the Divine) (2018), ISBN: 9788831928304. 